\title{
Trichofolliculoma: A new dermoscopic pattern
}

\author{
Sara Mai ${ }^{1}$, Meriem Meziane ${ }^{1}$, Kaoutar Znati $^{2}$, Karima Senouci ${ }^{1}$
}

${ }^{1}$ Department of Dermatology, University Hospital Ibn Sina, Rabat, Morocco, ${ }^{2}$ Department of Histopathology, Ibn Sina

University Hospital, Rabat, Morocco

Corresponding author: Dr. Sara Mai, E-mail: sara250190@gmail.com

Sir,

Trichofolliculoma is an uncommon benign hairfollicle hamartoma usually appearing in adulthood as a solitary papule or nodule on the face or scalp. In some cases, the lesion manifests itself as a central dilated pore with a small tuft of white hairs, which corresponds histologically to a primary dilated hair follicle with secondary immature hair follicles emerging from it. The dermoscopic features of trichofolliculoma have rarely been described and are usually nonspecific. We report a new dermoscopic pattern of trichofolliculoma.

A seventeen-year-old female presented herself with a two-year history of a small itchy papule on the right cheek. The patient described occasional discharge of whitish filamentary material from the center of the lesion. A physical examination revealed a skin-colored pinhead-sized papule with a central dilated pore (Fig. 1).

A dermoscopic examination revealed a pinkish structureless lesion with a tuft of thin fuzzy white hairs emerging from a central opening surrounded by a horny plug (Fig. 2).

An excisional biopsy was performed as the patient was very annoyed by the itching. A histological examination revealed a dysmorphic hair follicle with a central invagination filled with keratinous material and multiple secondary follicles radiating around it. These elements were consistent with the diagnosis of trichofolliculoma (Fig. 3).

Trichofolliculoma is a benign hair-follicle tumor first described by Meischer in 1944 [1]. It is mostly seen in adulthood but may also occur in children or even

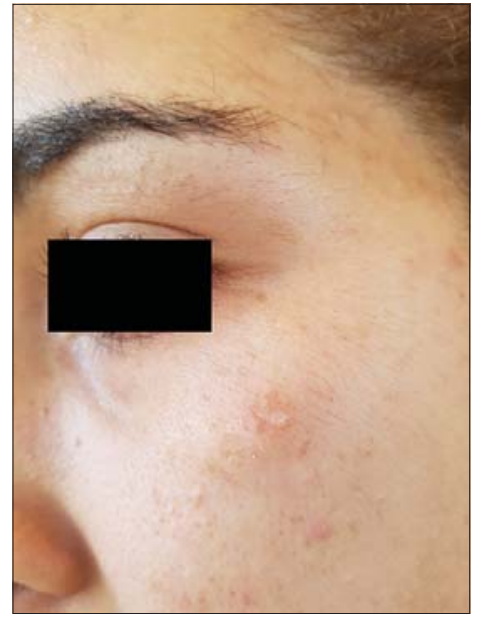

Figure 1: The clinical aspect of the lesion with no particular orientation.

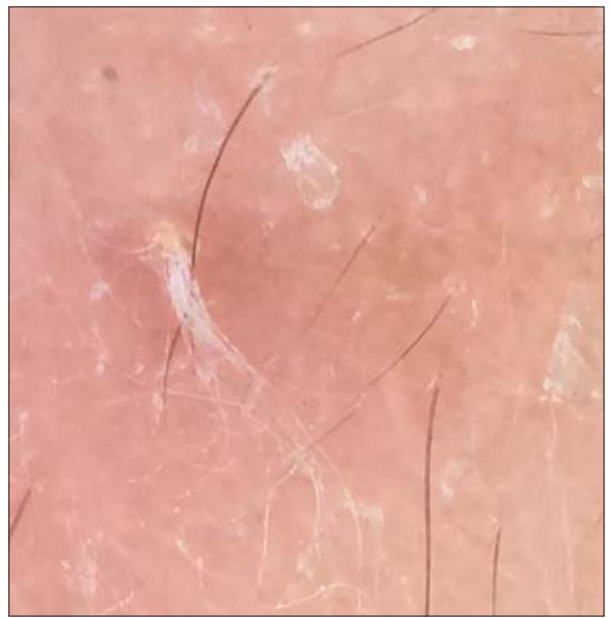

Figure 2: A pinkish structureless lesion with a tuft of thin white hairs emerging from a central opening.

newborns [2]. It manifests clinically as a solitary papule affecting the face and scalp, sometimes with a dilated pore and a small tuft of hair in the middle. However, these specific features are not always present and the clinical aspect may be very misleading.

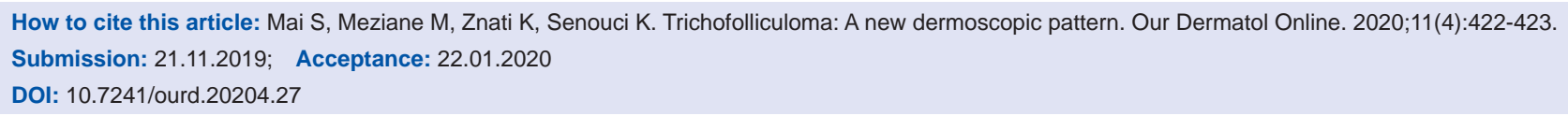




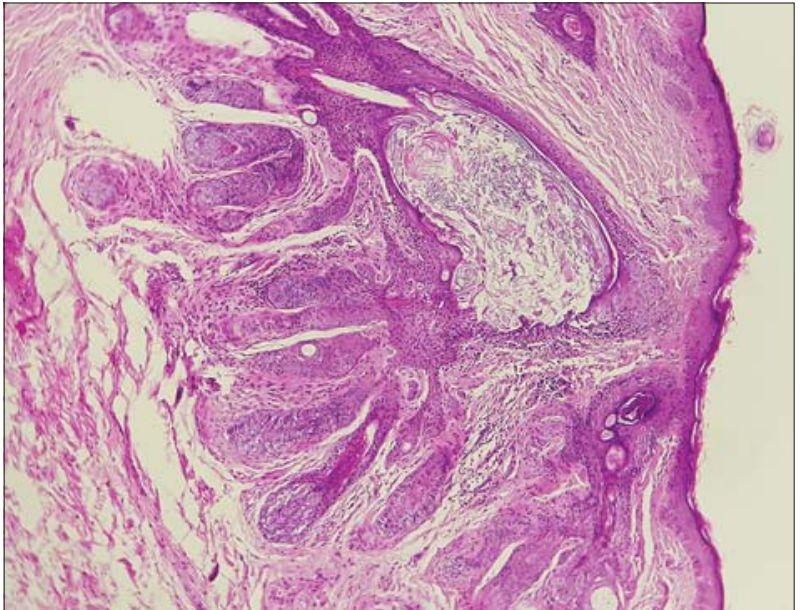

Figure 3: Multiple secondary hair follicles radiating from a primary dysmorphic follicle with a central cavity filled with keratin and sebum.

Dermoscopy may be particularly helpful to exclude differential diagnoses, especially malignant tumors. The dermoscopic features of trichofolliculoma have rarely been described in the literature. Panasiti et al. described a case with a "firework" pattern with a central brown zone and radial dark brown projections [3]. Jégou-Penoui et al. reported a case of a pinkish hemispherical well-limited papule with a central disruptor and fine peripheral serpiginous vascularization with a centripetal disposition [2]. Garcia-Garcia et al. reported a late-stage lesion that appeared as a well-defined, bluish nodule with a white-pink central area, shiny-white structures, dotted vessels, and a central scale [4].
This particular aspect of a white hair tuft that may be observed clinically has never been described on dermoscopy before.

\section{Consent}

The examination of the patient was conducted according to the principles of the Declaration of Helsinki.

The authors certify that they have obtained all appropriate patient consent forms, in which the patients gave their consent for images and other clinical information to be included in the journal. The patients understand that their names and initials will not be published and due effort will be made to conceal their identity, but that anonymity cannot be guaranteed.

\section{REFERENCES}

1. Miescher G. Un cas de trichofolliculome. Dermatologica. 1944;89:193-4.

2. Jégou-Penouil M-H, Bourseau-Quetier C, Cajanus S, Rigon J-L, Risbourg M, Kluger N. Trichofolliculomes: revue rétrospective de 8 cas. Ann Dermatol Vénéréol. 2015;142:183-8.

3. Panasiti V, Roberti V, Lieto P, Visconti B, Calvieri S, Perrella E. The "firework" pattern in dermoscopy. Int J Dermatol 2013;52:1158-9.

4. Garcia-Garcia SC, Villarreal-Martinez A, Guerrero-Gonzalez GA, Miranda-Maldonado I, Ocampo-Candiani J. Dermoscopy of trichofolliculoma: a rare hair follicle hamartoma. J Eur Acad Dermatol Venereol 2017;31:e123-4.

Copyright by Sara Mai, et al. This is an open access article distributed under the terms of the Creative Commons Attribution License, which permits unrestricted use, distribution, and reproduction in any medium, provided the original author and source are credited.

Source of Support: Nil, Conflict of Interest: None declared. 